SAKAI SAMBAYAN — Jurnal Pengabdian kepada Masyarakat

\title{
PEMETAAN DRONE DAN OPTIMALISASI POTENSI GEOWISATA DANAU TIRTA GANGGA, DESA SWASTIKA BUANA KEC. SEPUTIH BANYAK, LAMPUNG TENGAH
}

\author{
I Gede Boy Darmawan ${ }^{1 *}$, Suharno ${ }^{2}$, Rahmi Mulyasari ${ }^{3}$, Hesti $^{4}$ \\ Jurusan Teknik Geofisika Universitas Lampung, Bandar Lampung \\ Jl. Prof. Sumantri Brojonegoro No.1 Bandar Lampung 35145 \\ Penulis Korespodensi : igedeboy@staff.unila.ac.id
}

\begin{abstract}
Abstrak
Danau Tirta Gangga merupakan sebuah danau buatan yang terletak di Kabupaten Lampung Tengah, Kecamatan Seputih Banyak, tepatnya berada di Desa Swastika Buana. Danau ini memiliki luas sekitar 150 hektar dan digunakan oleh masyarakat untuk pengairan lahan pertanian sekitar 3000 ha di sekitar kawasan. Danau Tirta Gangga memiliki daya tarik tersendiri terhadap wisatawan lokal untuk menikmati keindahan alam dan pemandangannya. Namun beberapa kegiatan masyarakat menyebabkan aspek keindahan alam menjadi berkurang dan menimbulkan permasalahan pada suplai air baku untuk pertanian. Sehingga diperlukan suatu tindakan yang dapat mempertahankan fungsi awal dari danau ini bahkan menambahkan nilai keekonomisan bagi masyarakat. Pengabdian ini bertujuan untuk mengatasi permasalahan tersebut dengan memetakan potensi geowisata baru yang dapat dikembangkan dan dikelola oleh masyarakat,mengedukasi masyarakat dalam peningkatan kualitas dan keunggulan/ kearifan lokal yang berimbas pada peningkatan nilai ekonomi kawasan Danau Tirta Gangga dengan pemanfaatan teknologi informasi untuk media promosi (dengan Drone) profil kawasan wisata Danau Tirta Gangga. Manfaat dari pengabdian ini adalah terpetakannya potensi geowisata baru yang dapat dikembangkan dan dikelola oleh masyarakat serta terbentuknya media promosi video profil kawasan wisata Danau Tirta Gangga yang dapat disebarkan melalui media internet sehingga wisatawan dapat dengan mudah mengenal dan tertarik untuk berkunjung ke Danau Tirta Gangga.
\end{abstract}

Kata kunci: Danau, Tirta Gangga, Swastika Buana, Drone, Geowisata

\section{Pendahuluan}

Danau Tirta Gangga merupakan sebuah danau buatan yang terletak di Kabupaten Lampung Tengah, Kecamatan Seputih Banyak, tepatnya berada di Desa Swastika Buana. Danau ini memiliki luas sekitar 150 hektar dan digunakan oleh masyarakat untuk pengairan lahan pertanian sekitar 3 ribu ha yang berada di sekitar kawasan tersebut (Dinas PSDA Lampung Tengah, 2007). Sejak tahun 1980-an, Danau Tirta Gangga telah memiliki daya tarik tersendiri terhadap wisatawan lokal untuk menikmati keindahan alam dan pemandangannya. Pada hari-hari libur, umumnya masyarakat berkunjung hanya untuk menikmati suasana dan panorama alam yang didukung oleh adanya Patung dan Bangunan Pura di tengah danau.

Berdasarkan hasil penelitian (Iskandar, 2009) diketahui bahwa terdapat beberapa kegiatan masyarakat yang menyebabkan aspek keindahan alam di Danau Tirta Gangga menjadi berkurang yang salah satunya akibat menyusutnya air di danau saat musim kering atau kemarau. Kondisi ini juga menimbulkan permasalahan pada suplai air baku untuk pertanian di sekitar danau tersebut. Sehingga diperlukan suatu tindakan yang dapat mempertahankan fungsi awal dari danau ini bahkan menambahkan nilai keekonomisan bagi masyarakat. Salah satu tindakan tersebut adalah kegiatan rencana penataan kawasan Danau Tirta Gangga yang dilakukan oleh Dinas Pariwisata Kabupaten Lampung Tengah pada tahun 2007. Salah satu hasil dari kegiatan tersebut adalah penetapan site plan kawasan wisata dan Danau Tirta Gangga termasuk di dalamnya. Namun demikian, belum ada gambaran maupun informasi pengembangan potensi wisata lain di Danau Tirta Gangga selain pemandangan dan panorama alam, sehingga diperlukan suatu pemetaan dan identifikasi potensi tersebut.

Selain itu, pemanfaatan teknologi informasi juga belum dapat dimaksimalkan untuk membantu 
membangun profil dan promosi wisata di Danau Tirta Gangga oleh masyarakat setempat. Kondisi ini dapat kita lihat dari sedikitnya informasi detil terkait peta kawasan wisata, informasi pengelola objek wisata dan keunggulan/kearifan lokal objek wisata Danau Tirta Gangga. Perlunya pendampingan dalam penggunaan teknologi informasi untuk membuat video profil kawasan wisata yang memanfaatkan drone juga dapat menjadi salah satu aspek yang dapat dilakukan melalui kegiatan pengabdian kepada masyarakat.

\section{A. Konsep Geowisata}

Geowisata (geotourism) adalah kosakata yang relatif baru dalam kepariwisataan nasional. Istilah itu kurang populer dibanding ekowisata (ecotourism), atau agrowisata misalnya. Namun demikian, di dalam UU No. 9/1990 tentang kepariwisataan, selain wisata agro, baik ekowisata maupun geowisata memang tidak disebut-sebut (Brahmantyo \& Bachtiar, 2009; Rusita dkk., 2016; Walimbo dkk., 2017). Apa itu geowisata atau geotourism? Istilah geotourism muncul tak lebih tua dari pertengahan 1990-an. Seorang ahli Geologi dari Buckinghamshire Chilterns University di Inggris bernama Tom Hose diperkirakan menjadi orang yang pertama aktif memperkenalkan istilah itu. Ia misalnya menulis di Geological Society pada 1996 suatu makalah berjudul "Geotourism, or can tourists become casual rock hounds: Geology on your doorstep".

Jika di AS geowisata identik dengan ekowisata, di belahan benua lain, geowisata ditempatkan sebagian bagian dari wisata alam minat khusus yang prinsip-prinsipnya mengikuti kaidah-kaidah ekowisata. Geowisata sebagai bagian dari ekowisata bagaimana pun harus tunduk pada prinsip-prinsip berwisata yang berwawasan lingkungan dan berkelanjutan sesuai Kesepakatan Quebec 2002 (Fandeli \& Mukhlison, 2000; Fandeli, 2002; Brahmantyo dkk, 2017).

\section{B. Rumusan Permasalahan}

Ada tiga permasalahan yang ingin di jawab dengan kegiatan ini yaitu bagaimana memetakan potensi baru geowisata di Danau Tirta Gangga untuk mendukung peningkatan nilai keekonomisan kawasan. Kemudian bagaimana mengoptimalisasi peran serta masyarakat dalam peningkatan kualitas dan keunggulan/kearifan lokal yang berimbas pada peningkatan nilai ekonomi kawasan Danau Tirta Gangga. Terakhir adalah bagaimana membantu masyarakat dalam peningkatan pemanfaatan teknologi informasi untuk media promosi profil kawasan wisata Danau Tirta Gangga.

\section{Tujuan Kegiatan}

Secara khusus kegiatan ini bertujuan melakukan pemetaan potensi geowisata baru yang dapat dikembangkan dan dikelola oleh masyarakat di Danau Tirta Gangga untuk meningkatkan nilai keekonomisan kawasan. Kegiatan ini juga bertujuan untuk memberikan edukasi masyarakat tentang optimalisasi peran serta masyarakat dalam peningkatan kualitas dan keunggulan/kearifan lokal yang berimbas pada peningkatan nilai ekonomi kawasan Danau Tirta Gangga. Selain itu, kegiatan ini diharapkan dapat membantu masyarakat dalam peningkatan pemanfaatan teknologi informasi untuk media promosi (dengan Drone) profil kawasan wisata Danau Tirta Gangga.

\section{Manfaat Kegiatan}

Kegiatan ini diharapkan dapat memberikan manfaat kepada masyarakat di lingkungan danau seperti terpetakannya potensi geowisata baru yang dapat dikembangkan dan dikelola oleh masyarakat di Danau Tirta Gangga, sehingga memperkaya keragaman objek yang dapat dinikmati oleh wisatawan. Dengan kegiatan ini juga diharapkan teredukasinya masyarakat tentang peran serta mereka dalam peningkatan kualitas dan keunggulan/kearifan lokal sehingga berimbas pada peningkatan nilai ekonomi kawasan Danau Tirta Gangga.

Manfaat lainnya adalah dengan memanfaatkan Drone untuk membuat video. Terbentuknya media promosi (dengan Drone) berupa video profil kawasan wisata Danau Tirta Gangga yang dapat disebarkan melalui media internet sehingga wisatawan dapat dengan mudah mengenal dan tertarik untuk berkunjung ke Danau Tirta Gangga.

\section{Bahan dan Metode}

Untuk menjawab tantangan pengambilan data untuk pemetaan maka telah dikembangakan teknologi baru dalam eksplorasi sumber daya alam dengan menggunakan bantuan teknologi "UAV" (Unmanned Aerial Vehicle) atau Drone. Diharapkan UAV dapat digunakan sebagai alternatif solusi untuk survey eksplorasi sumber daya di Indonesia. 


\section{A. Bahan/Peralatan Drone}

Drone (UAV) atau disebut wahana udara tak berawak (Gambar 1) merupakan sebuah wahana terbang yang mempunyai kemampuan dapat beroperasi tanpa adanya pilot yang mengendalikan pesawat tersebut. Saat ini UAV telah berkembang pesat seiring dengan kemajuan di bidang teknologi elektronika dan komunikasi. UAV pada saat ini telah dapat digunakan untuk membantu mamantau pengawasan kebakaran hutan, foto udara, pencarian korban bencana dan lain-lain. UAV dapat dikendalikan secara manual maupun secara otomatis.

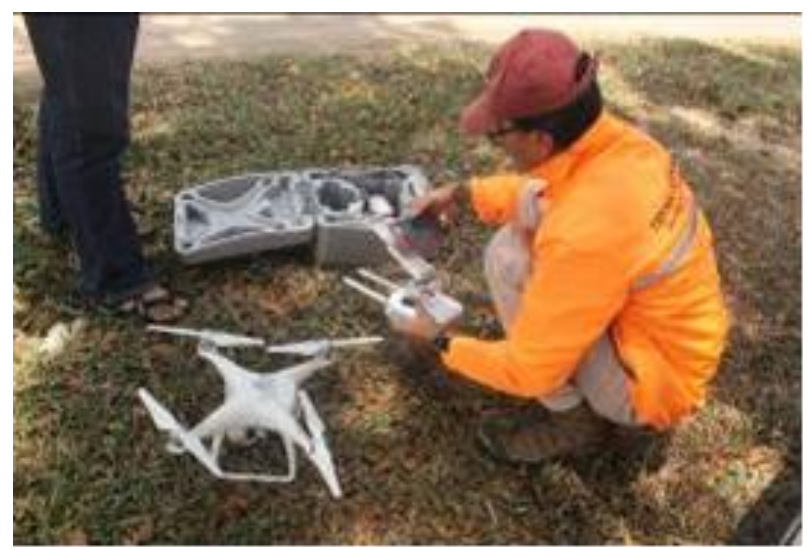

Gambar 1. Persiapan penggunaan drone Phantom 4 untuk mengambil gambar di udara.

Pada kegiatan ini, Drone yang digunakan adalah Drone Phantom 4 dari DJI. Drone ini memiliki empat baling-baling dan dilengkapi dengan kamera. Kamera dengan resolusi $20 \mathrm{MPx}$ mampu melakukan pengambilan video dan pemotretan udara dengan cukup baik. Kamera ini juga telah dilengkapi dengan gimbal yang mampu menstabilkan getaran dan guncangan saat pengambilan gambar sambil terbang.

\section{B. Metode dan Tahapan Kegiatan}

Kegiatan yang akan dilaksanakan meliputi studi pustaka tentang pengembangan ekowisatageowisata, melakukan visualisasi bentang alam, geologi, foto dan video pada obyek Danau Tirta Gangga dan sekitarnya. Terakhir mendeskripsikan obyek wisata, diskusi (FGD) dan pembuatan promosi wisata.

Prosedur kerja yang akan diterapkan dalam kegiatan pengabdian ini untuk mendukung penerapan IPTEKS/metode yang ditawarkan meliputi pemetakan kondisi alam dengan menerbangkan Drone Phantom 4 untuk mengakuisisi foto dan video dari atas Danau Tirta Gangga. Hasil foto dan video dikombinasikan dengan pemetaan potensi melalui pengamatan langsung di lapangan dengan melibatkan mitra dan membuat analisis potensi pengembangan wisata Danau Tirta Gangga. Pembuatan video profil wisata untuk media promosi yang dapat dipublikasikan melalui internet serta membantu publikasikan hasil tersebut.

\section{Hasil dan Pembahasan}

Hasil-hasil yang sudah dicapai dari kegiatan ini meliputi pertemuan dengan tokoh masyarakat dan POKDARWIS wisata Tirta Gangga dalam mendiskusikan rencana pemetaan kawasan wisata Danau Tirta Gangga. Diskusi bersama beberapa pengurus desa dan anggota POKDARWIS serta Peninjauan lokasi dan kondisi Danau Tirta Gangga bersama beberapa pengurus desa dan anggota POKDARWIS (Gambar 2).

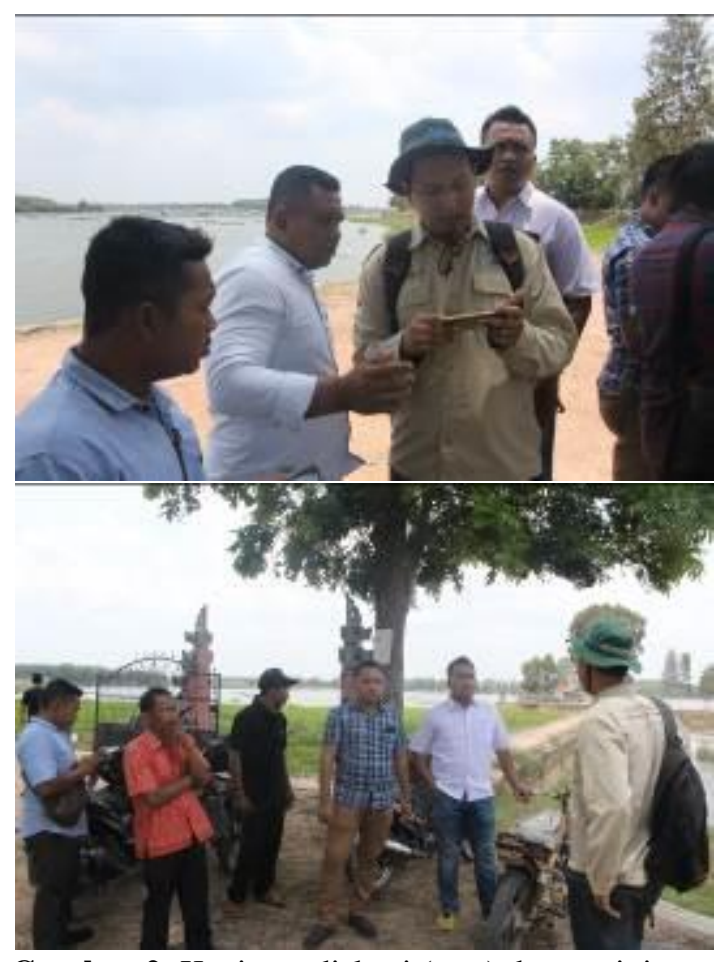

Gambar 2. Kegiatan diskusi (atas) dan peninjauan lokasi (bawah) Danau Tirta Gangga bersama Pokdarwis dan pengurus desa Swastika Buana.

Hasil peninjauan dilanjutkan dengan kegiatan pemetaan dan pengambilan video dengan menggunakan drone di kawasan wisata Danau Tirta Gangga. Kegiatan ini meliputi Persiapan dan setup drone untuk pengambilan gambar dan video serta pemilihan jalur terbang dan lokasi objek gambar 
maupun video bersama dengan POKDARWIS di kawasan Danau Tirta Gangga. Beberapa hasil pemotretan udara oleh drone di kawasan wisata Danau Tirta Gangga ditunjukkan oleh Gambar 3.
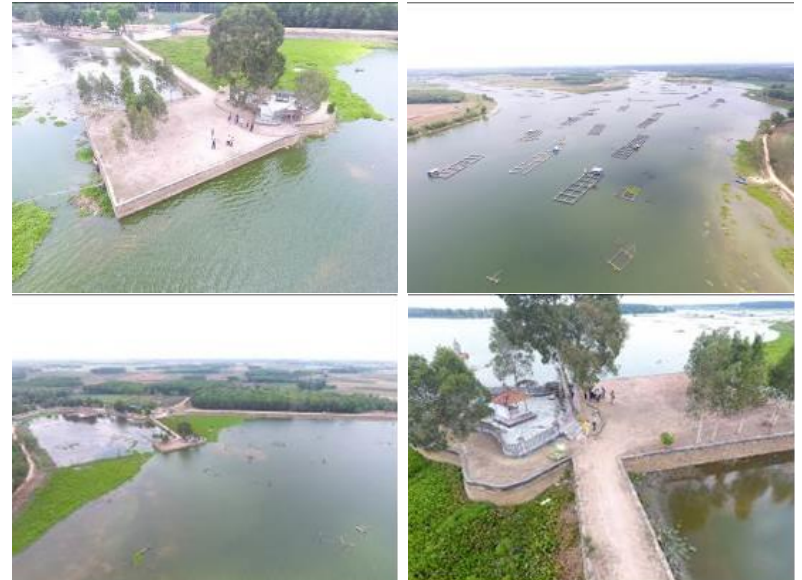

Gambar 3. Beberapa hasil pemotretan udara dan pengambilan video dari drone di Danau Tirta Gangga.

Selain itu, kegiatan ini juga menghasilkan pengamatan potensi sumber daya air dan pengambilan sampel (Gambar 4) untuk mengetahui kualitas air di Danau Tirta Gangga (Tabel 1).

Tabel 1. Hasil pengukuran kualitas air di kawasan wisata Danau Tirta Gangga Desa Swastika Buana, Kec. Seputih Banyak, Lampung Tengah.

\begin{tabular}{ccccl}
\hline No & $\mathbf{p H}$ & $\begin{array}{c}\text { TDS } \\
(\mathbf{p p m})\end{array}$ & $\begin{array}{c}\mathbf{E C} \\
(\boldsymbol{\mu s} / \mathbf{c m})\end{array}$ & Kualitas \\
\hline 1 & 5,65 & 39 & 76 & $\begin{array}{l}\text { Baik namun } \\
\text { asam } \\
\text { Baik namun } \\
\text { asam dan } \\
\text { rendah } \\
\text { mineral } \\
\text { terlarut } \\
\text { Sangat asam } \\
\text { dan kurang } \\
\text { mineral }\end{array}$ \\
\hline
\end{tabular}

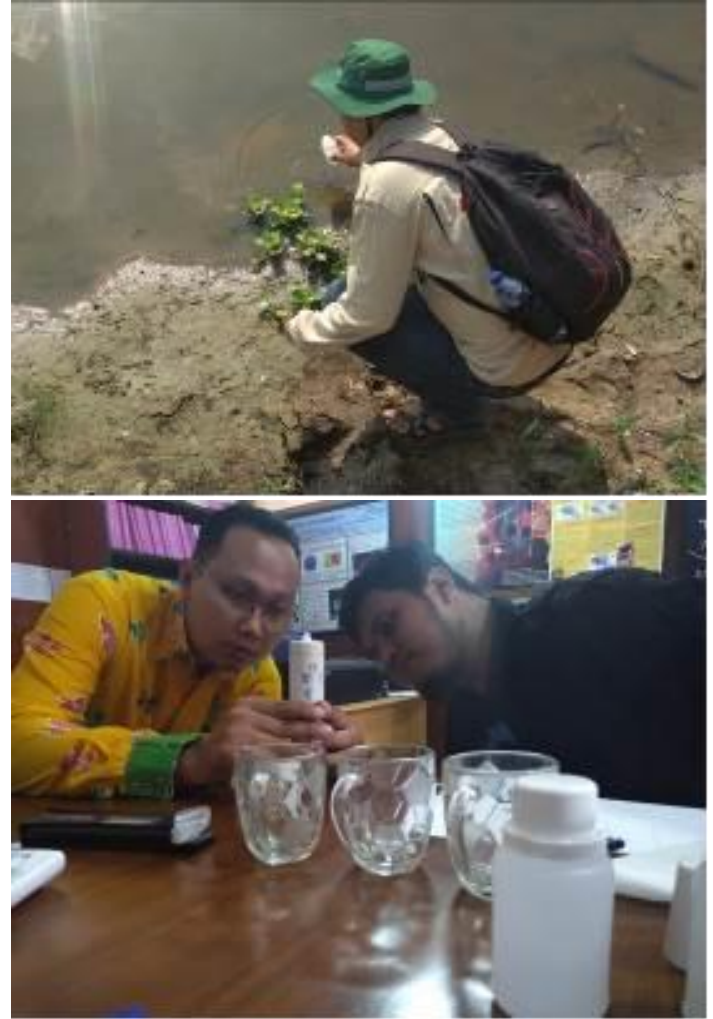

Gambar 4. Kegiatan pengambilan sampel air dan pengujian kualitas air danau di laboratorium.

Seluruh kegiatan tersebut telah berhasil dilakukan dengan baik dan menghasilkan foto dan video pengembangan wisata di Desa Swastika Buana. Pemetaan potensi baru dan pengembangan kawasan wisata di Danau Tirta Gangga telah teridentifikasi dan telah ditentukan masterplan oleh pemerintah desa yang mampu meningkatkan kenyamanan dalam berwisata. Video promosi wisata telah dibuat dengan memanfaatkan teknologi drone agar mampu meningkatkan daya tarik wisata ke Danau Tirta Gangga. Beberapa kekurangan dari hasil kegiatan ini adalah peta detil kawasan wisata belum dapat dibuat dikarenakan kondisi angin yang sangat kuat saat akuisisi image dengan menggunakan drone. Peta masterplan belum dibuat secara digital sehingga dokumen masih berbentuk gambar manual dan dimiliki oleh kepala kampung.

Pengembangan potensi wisata Danau Tirta Gangga dapat ditingkatkan dengan promosi potensi wisata melalui media sosial, membuat pamflet dan foster untuk sarana promosi di pameran. Penambahan obyek wisata sekitar perlu dilakukan, diantaranya kolam pemancingan, wisata kemah, dan flying fox serta panggung pertunjukkan. 
Pembuatan peta lokasi wisata yang dipasang di area setempat.
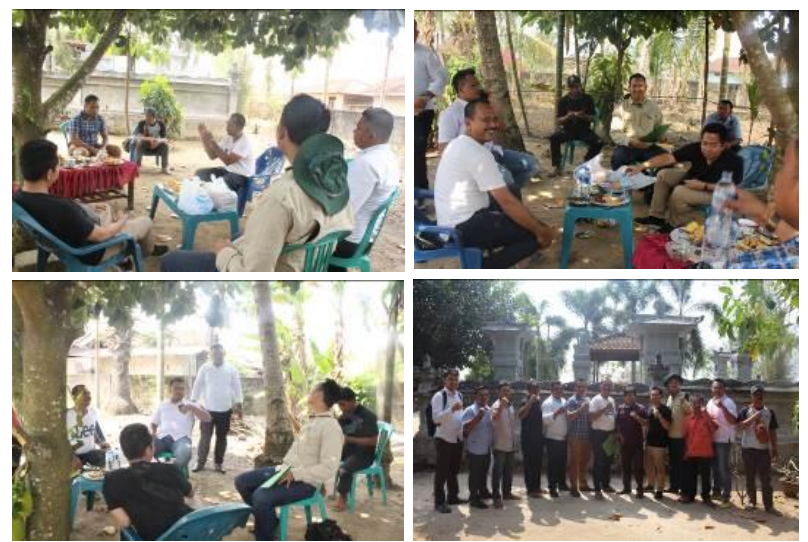

Gambar 5. Kegiatan diskusi hasil pemetaan dan identifikasi potensi geowisata di Danau Tirta Gangga.

Perlunya pembuatan lokasi parkir dan kantin serta fasilitas MCK. Pembuatan jalur tracking dan wisata air dengan perahu atau kano, dan pembuatan taman bunga dan lokasi foto di tengah danau dengan jembatan bambu atau kayu akan semakin mengoptimalkan potensi di Danau Tirta Gangga.

\section{Kesimpulan}

Secara umum, dengan adanya pemetaan dan identifikasi lokasi wisata serta pembuatan video promosi dengan drone, potensi di kawasan Danau Tirta Gangga dapat dioptimalisasi. Beberapa lokasi lainnya dapat menambah ragam lokasi wisata bagi wisatawan. Pengembangan wisata Danau Tirta Gangga akan sangat baik jika POKDARWIS dan Kepala Kampung dapat bersinergi dalam pengembangan selanjutnya. Pelajaran terpenting dalam kegiatan ini adalah bahwa potensi wisata bentang alam khususnya di Danau Tirta Gangga yang ada sudah dipahami dengan baik oleh kelompok masyarakat setempat, tetapi perlu pendampingan agar potensi tersebut dapat berdayaguna dan bermanfaat untuk masyarakat setempat. Penambahan fasilitas wisata merupakan sebuah keharusan, dan sinergi pemerintahan, masyarakat dan kelompok relawan perlu didayagunakan secara maksimal.
Akademisi, masyarakat umum dan Kelompok Sadar Wisata (POKDARWIS) harus diajak dan dimotivasi tentang kegiatan pemetaan potensi pariwisata (secara sederhana) dari segi bentang alam, sumber daya air, lingkungan, budaya dan teknologi, juga pengelolaan potensi desa wisata dan mempromosikannya ke masyarakat luas. Sehingga potensi alam di lokasi mereka dapat didayagunakan dan memberikan manfaat bagi masyarakat setempat.

\section{Ucapan Terima Kasih}

Terima kasih disampaikan kepada LPPM UNILA yang telah mendanai kegiatan ini sebagai bagian dari luaran PkM Pemula No. 3482/UN26.21/PM/ 2019.

\section{Daftar Pustaka}

Brahmantyo, B dan Bachtiar, T. (2009). Wisata Bumi Cekungan Bandung. Truedee Pustaka, Bandung.

Brahmantyo H., Baiquni M., Fandeli C., \& Widodo T. (2017). Persepsi masyarakat setempat dan pegawai pemerintah daerah terhadap dampak pembangunan pariwisata : studi kasus di kawasan Kota Tua. Jurnal Khasanah Ilmu, 8(1), 10-19.

Dinas PSDA Lampung Tengah. (2007). Rencana Induk Pengembangan Pariwisata Daerah Lampung Tengah. Sekretariat Kabupaten Lampung Tengah, Gunung Sugih.

Fandeli, C. \& Mukhlison. (2000). Pengusahaan Ekowisata. Fakultas Kehutanan Universitas Gadjah Mada, Bulaksumur, Yogyakarta.

Fandeli, C. (2002). Perencanaan Kepariwisataan Alam. Fakultas Kehutanan Universitas Gadjah Mada, Bulaksumur, Yogyakarta.

Iskandar, D. (2009) Valuasi Ekonomi Manfaat Sumber Daya Air Danau Tirta Gangga Kabupaten Lampung Tengah Untuk Pertanian dan Wisata. Tesis, Universitas Padjadjaran.

Rusita, Walimbo, R., Sari, Y. \& Yanti, M. (2016). Studi Potensi Obyek dan Daya Tarik Wisata Alam Air Terjun Wiyono di Taman Hutan Raya Wan Abdul Rahman, Provinsi Lampung. INFO TEKNIK, 2(17), 165-186.

Walimbo, R., Wulandari, C. \& Rusita. (2017). Studi Daya Dukung Ekowisata Air Terjun Wiyono di Taman Hutan Raya Wan Abdul Rahman Provinsi Lampung. Jurnal Sylva Lestari, 1(5), 47-60 